\title{
Risk Management in the United Kindom - a Personal Retrospect
}

\author{
by Dennis Farthing*
}

\section{Introduction}

This text concerns itself primarily with matters form a United Kingdom standpoint but with insights into the position in Europe.

As a separate management discipline, the concept of Risk Management as a theoretical basis for handling risk first became evident in the UK some after the second World War. Its development into a defined role and practical application came later. It has developed on two planes or in two directions:

1) The expansion of the role of 'insurance buyer' into that of Risk Manager and the creation of a recognized discipline ;

and

2) the educational need to improve the intellectual and practical capability of today's and tomorrow's Risk Manager.

The second is a direct product of the former.

\section{Early interest}

Many larger Corporations in the United Kingdom maintain insurance buying departments either in the guise of "captive" insurance companies, or as a separate Head Quarters department, particularly the Chemical and Oil majors, and Engineering companies.

Historically, the function of insurance buyer has rested generally within the Bailliewick of the Company Secretary. Insurance being perceived as the financial protection for the Shareholders, cushioning them from the results of untoward and fortuitous events, mostly those of 'natural causes'. In due course, it became apparent that as a specialist job it required expert attention and appropriate qualification of the practitioner. With employment of qualified and experienced insurance personnel, there was a natural movement toward a closer examination of the product being purchased, its price and its efficacy. The dedicated professional not only had more time for these activities than hitherto made available by busy Company Secretaries but he brought greater skill and understanding to the solution of risk financing needs. He also found colleagues with similar problems and needs in other Companies with whom to share his ideas and concerns.

\footnotetext{
* Tillinghast, UK.
} 


\section{The founding of AIMIC}

In the 50's and early 60's many of this new and extending breed of insurance buyers would discuss issues of the day at ad hoc and informal meetings. This natural progression was toward formality and eventually, after one or two abortive attempts, an Association of those involved in Insurance buying was formed in December 1963, then known as The Association of Insurance Managers in Industry and Commerce. The American Society of Insurance Managers (ASIM) was as yet relatively unknown to Buyers in England but soon Douglas Barlow, President of ASIM was destined to visit England and change the perspective of English Insurance Managers in a decisive manner.

AIMIC was formed on a private rather than Corporate membership basis and remains so today, reflecting the source of interest and the desire to maintain individual identity within the group rather than a collective view. This has been evident in several contentious issues where the "corporate" response to a problem has been criticised on the basis that AIMIC, (unlike ASIM/RIMS), does not represent its members as a power block.

As a result of the more formal and structured meeting of minds, major differences in sophistry, outlook and approach, led to a steep and rapid learning process for many and a quantum leap in understanding the more progressive methods of financing risk.

At this time the emphasis was on changing the structure of the industrial insurance portfolio to reflect Industry's increasing ability and willingness to dispense with unnecessary insurance and bear some of its own risk. At the AIMIC Conference in 1967, the first Paper ${ }^{1}$ was on the subject of Self Insurance, putting the insurance world on notice that risk-retention (as we now know it) was on the agenda and that buyers were being selective in termś of their insurance needs. This followed at the 1968 Conference by a Paper on the subject of risk management delivered by William Horrigan, then Lecturer in Economics at Nottingham University. ${ }^{2}$

Now awareness was growing for the need to question the whole ethos of using insurance as the primary means of addressing risk and for a more holistic approach to the subject of managing risk. A number of publications, some now standard text books, began to appear in the UK. ${ }^{3,4+5}$ These texts became the base for Risk Management as a discipline.

The movement away from insurance buying to risk management was given further impetus when in 1969, Massey Ferguson, (under the guidance of Douglas Barlow, Corporate Risk Manager), made the first designated Risk Manager appointment in the UK. Barlows' pre-eminence in the field was quickly recognised and, as the President of ASIM, started a close relationship between ASIM (American Society of Insurance Management) and AIMIC, culminating in Barlow being the first North American to be invited to address an AIMIC Conference: the subject? Risk Management !

As mentioned earlier, Barlows intervention marked a watershed in the affairs of AIMIC leading to the promotion of Risk Management as a recognised management dis-

${ }^{1}$ AIMIC to AIRMIC - the First 25 years: AIRMIC History by the 1263 Club 1991. 1967.

${ }^{2}$ Aspects of Self-insurance in an Insurance Programme: D. J. Farthing - AIMIC Conference

3 Risk Management and Insurance : Prof. W. Horrigan 1969.

4 The Growing Job of Risk Management: American Management Association.

${ }^{5}$ Risk Management in the Business Enterprise: Meir \& Hedges 1963. 
cipline and the goal of the Insurance Manager. In 1974, AIMIC changed its name to AIRMIC by inserting "Risk" into its title to become the Association of Risk and Insurance Managers in Industry and Commerce.

This was not accomplished without fierce debate about the validity of the change, many were still of the view that Risk Management was Insurance Management dressed up in a new suit of clothes. The metamorphosis was long in gestation and even today Commentators in the UK continue to express doubts that this is a distinction without a difference.

For all that, there has been an evolutionary change. ${ }^{6}$ In the carlier days, much time and effort was spent getting involved in "nuts and bolts" activities of Safety and Fire Engineering. The debate on the Environment and Insurers' response to the Buyers' needs has pushed Risk Managers into the front line of Corporate discussion of risk. Senior Risk Managers within AIRMIC have established a credibility with their management which puts them in possession of information in a much more timely fashion and involves them in the strategic issues involving risk and business decision making. Their views are sought by Management before the event rather than as a "fire fighter" afterwards.

\section{The Market}

The response from the indigenous insurance market to this new coalescence of insurance Buyers was "wait and see". Some of the major insurance companies privately took the view that this embryonic but burgeoning Association would lead to "ganging up" by the insurance buyers now able to communicate quickly and openly with each other and each in possession of the latest data on products and prices, to the general detriment to the very cosy position enjoyed by the Insurers hitherto. Brokers also saw an early threat to their preeminent position of insurance services providers and took the stance of "insurance buyer minder" to head off what they could see would be a call for more accountability for their commission income and a demand to share the spoils. Brokers, being more commercially aware and market place oriented, saw that their best interest would be served by supporting AIMIC rather than opposing it and set out to create a favourable climate in spite of the general antipathy toward them.

Not all the composite companies were averse to the idea of risk management. The Commercial Union very boldly and successfully spun off a Risk Management consultancy under the Managing Directorship of Ken Duffy in the face of opposition deep in his own Company. CURM (as it was known) forged a friendly relationship with AIRMIC and was well received and remains so today. CURM was in its time a novel feature for an insurance company to spawn and foster a subsidiary, with a business strategy counter to its core business and apparently bent on reducing the need to buy insurance, and dedicated to alternative risk financing techniques. That CURM was able to operate and maintain an arms length relationship with its parent says much for the management skills of it's M.D.

A number of other consultancies were established, some were of greater longevity than others. One such more successful enterprise was Keith Shipton Developments, a subsidiary of C.T. Bowring, Insurance Brokers. Other Broker sponsored consultancies were also established, all more or less dependent on the Parent core business activity for it's client base. Generally, Risk Management consulting has not had an easy ride in the UK largely

\footnotetext{
${ }^{6}$ The Advantages of Risk Management: D. J. Farthing, F-T Conference, London, 1971.
} 
because of the predominant Broker presence. In later years, with the emergence of independent consultancies such as Tillinghast, others, some of which have been spun off from Accounting and Auditing organisations (and who perceived a niche market), have moved into the field of risk management with some success. There now is a core of good quality, unbiased advice available on the subject, with many small businesses offering specialist services to support Risk Managers.

\section{Education}

The earliest efforts to Educate, (rather than train), came from Management Centre Europe. A number of two day Seminars were held during the early 70's which were well attended and continued for several years. Many of the emergent Consultancies learned their trade at these Seminars which were particularly well patronised by Skandinavian Insurers, anxious to be in the forefront of any changes. In UK, the British Institute of Management also mounted one or two such Seminars and AIRMIC continued to feature Risk Management issues at its Annual Conference.

The Universities too, were by now expressing an interest in the subject and at Nottingham, Dr. (now Professor) Bob Carter continued to feature it in his Industrial Economics curriculum as did Professor Bill Horrigan before him and in his new position at Sussex before leaving for Australia. It was Dr. (now Professor) Gordon Dickson of Glasgow College who, in the 80's, introduced the first (and only) Degree in Risk Management in the UK.

The premier Insurance education body in UK is the Chartered Insurance Institute which introduced a Risk Management option into its Syllabus for the Fellowship Diploma in the late 70's with a complete text book covering the subject. Much of the text was based on the Kluwer Harrap "Risk Management Manual" 7 both introduced the full spectrum of Risk Management subjects including Statistics and the Theory of Risk and Uncertainty.

AIRMIC too, had for long given thought to establishing an external qualification for Risk Management but the structure of membership was so restrictive that such a course was not viable. Under the Chairmanship of Roger Miller, recently appointed Executive Secretary of AIRMIC, a Professional Qualification Committee was established to re-examine the viability of a professional qualification in Risk Management. With advice from Professor Dickson of Glasgow, a syllabus was constructed and a proposal put to the Council of AIRMIC that a separate educational entity should be formed, open to everyone and not just those employed as Risk Managers in industry (subject to minimum standards of experience and education) and in 1986 the Institute of Risk Management was launched with open support from Brokers and a mixed, but eventual, support from insurers.

From the outset, the Institute adopted a fresh approach to the problem based on the premises that:

(a) The next generation of Risk Manager would need to be of higher calibre than the last;

(b) to attract the right candidates, the Diploma should offer other career opportunities outside Risk Management (R.M. being a desirable path to other, apparently more prestigious jobs); and,

\footnotetext{
7 The Handbook of Risk Management, Kluwer Harrap.
} 
(c) The Syllabus should be of sufficient breadth and high standard as to permit a Diploma Holder to demonstrate his academic capability in other management disciplines such as Treasury, Control, Audit, etc.

The Syllabus then adopted comprised the following subjects:

1) Risk and the Business Environment.

2) Business Finance.

3) Risk Analysis.

4) Occupational Safety and Health.

5) Physical Contol of Risk.

6) Insurance.

7) Liability Exposures.

8) Risk Financing.

9) Corporate Risk Management.

Early experience showed that the course of three years was proving a little daunting in terms of time and commitment and living up to its dynamic promise, changes were made to permit early exit with a lesser Diploma but with an option to continue with the remainder at some time in the future.

The full Course leads to Graduate Diploma with Fellowship following after the requisite period of experience. At the halfway mark, Students receive an Associate Diploma provided they have elected to study the first and third of the above subjects and two others not connected to their working discipline.

This new concept in Risk Management education was quickly recognised as the way to go by other Countries (with the notable exception of the U.S.) and similar Institutes have been formed in other Countries (Australia and South Africa). In Europe, AEAI the 'federal' or 'co-operative' of European Risk Management Associations (Association Européenne des Assurés de L'Industrie) has now taken the initiative in the adoption of an International recognised type of Diploma based on "core subjects" similar in content to The UK IRM Syllabus. Already several European Countries have Risk Management Faculties in their Universities (e.g. France and Italy) which will now include these core subjects. The end result will be a Diploma peculiar to the National needs of the Students' domicile but containing what is internationally considered as a minimum scope of knowledge for the discipline, validated by the local Risk Management Association and endorsed by AEAI. Hope is that through the offices of IFRIMA (the International Federation of Risk and Insurance Management Associations), the scheme can be extended world-wide, given total mobility to the Risk Manager of tomorrow as has his counterpart in Accounting, Marketing, etc.

\section{Conclusion}

Risk Management in UK started at the then conventional wisdom of the classic steps Analysis, Control and Financing. ${ }^{8}$ Definitions abounded but with little real meaning. The very structure drove Risk Managers toward the "hands-on" approach, getting themselves involved in Safety, Security, etc. - "Jack-of-all-trades-master-of-none". Finding themselves

8 The role of the Risk Manager in Industry \& Commerce: J. Parkinson 1976. 
in a position of apparent (assumed?) responsibility for such disparate operations but organisationally unable to exercise control over them, doubts arose as to the very viability of the discipline. Peter Schroeder of the Zurich Insurance Company at a recent Conference in London in 1991 even forecasted the return of the good old plain Insurance Manager!

Risk Management as a discipline, although still to some extent without a definitive role, has become recognised as an important part of.Corporate survival, paradoxically from the upsurge of the environmental matters and the implications for Industry and the adoption of Total Quality Management as a way of life for many Companies. The role is seen as the source of advice to the top echelons of business decision makers as to the potential "risky-ness" (in terms of Hazard risk) of strategic or business decisions; as a setter of Guidelines on matters pertaining to the discovery and management of risk; as the auditor of management compliance with the Corporate need to reduce exposure to risk; and of evolving novel and cost-conscious solutions to the financing of risk.

As to education, the frame-work is now well established. Changes are inevitable if only to maintain the dynamism. Up-grading of the subject matter and its extention to other risk areas must come. For the immediate future the impetus is in research. Much is yet to be done in terms of defining role and purpose to the satisfaction of industrial management; improving the techniques by which risks can be measured; resource deployment trade-offs determined; and priorities for attention established. 